\title{
PREDIKSI MASA SUBUR PADA WANITA MENGGUNAKAN PEMODELAN STATE SPACE BERBASIS SUHU BASAL TUBUH
}

\author{
Vinna Rahmayanti Setyaning Nastiti ${ }^{1)}$, Diah Risqiwati ${ }^{2)}$, Adwin Nugroho Siswoyo ${ }^{3)}$ \\ 1), 2), 3) Teknik Informatika, Universitas Muhammadiyah Malang \\ Jl. Raya Tlogomas No 246 Malang, Jawa Timur \\ Email : vinastiti@umm.ac.id ${ }^{1)}$,diah.risqiwati@gmail.com ${ }^{2)}$,adwinnugroho16@gmail.com ${ }^{3)}$
}

\begin{abstract}
Abstrak
Mengamati perubahan yang dialami tubuh selama menstruasi akan memberikan petunjuk penting tentang status kesuburan. Salah satu metode yang dianggap paling efektif dan mudah untuk diimplementasikan adalah dengan pemantauan suhu basal tubuh. Pada dasarnya, suhu basal tubuh (BBT) adalah kondisi dimana suhu berada pada level terendah. Masuknya masa subur ditandai oleh sedikit penurunan suhu, diikuti oleh kenaikan secara tiba-tiba setidaknya $0,2{ }^{\circ} \mathrm{C}\left(0,4{ }^{\circ} \mathrm{F}\right)$ selama 48 jam berikutnya. Tentunya siklus masa subur tesebut termasuk dalam data deret waktu dikarenakan datanya saling berhubungan satu sama lain yang berurutan, disusun dari satu objek yang terdiri dari beberapa waktu periode. Salah satu metode prediksi data deret waktu adalah state-space. Teknik yang digunakan di dalam state-space adalah memisah waktu masa lalu dengan masa sekarang. Oleh karena itu pada penelitian di prediksi masa subur wanita berbasis suhu basal tubuh menggunakan pemodelan state-space, hasilnya sangat baik dengan akurasi rata-rata kesalahan prediksi dibawah $5 \%$
\end{abstract}

Kata kunci: Masa subur wanita, suhu basal tubuh, data deret waktu, state space.

\section{Pendahuluan}

Mengamati perubahan yang dialami tubuh selama menstruasi akan memberikan petunjuk penting tentang status kesuburan. Salah satu metode yang dianggap paling efektif dan mudah untuk diimplementasikan adalah dengan pemantauan suhu basal tubuh. Pada dasarnya, suhu basal tubuh (BBT) adalah kondisi dimana suhu berada pada level terendah. Biasanya, suhu terendah yang dicapai oleh tubuh adalah ketika istirahat atau tidak sedang melakukan aktivitas apapun (Ika, 2018). Untuk memahami kesuburan seorang wanita, tentunya yang harus diketahui adalah tentang bagaimana teknik pengukuran dan penggambaran suhu basal tubuh bekerja.

Peningkatan suhu basal tubuh yang terjadi sekitar waktu ovulasi adalah karena peningkatan produksi progesteron, yang menghasilkan panas yang lebih besar di dalam tubuh. Biasanya, suhu basal tubuh tetap stabil, dengan fluktuasi kecil, selama paruh pertama siklus (fase praovulasi). Ini turun sedikit sebelum ovulasi dan kemudian naik antara $0,2^{\circ} \mathrm{C}$ sampai $0,5^{\circ} \mathrm{C}$ (Aminnudin et al, 2018) dan tetap naik sampai sebelum atau selama periode menstruasi, ketika jatuh lagi, Ini dikenal sebagai pola biphasic. Jumlah kenaikan suhu bervariasi dari wanita ke wanita (Yulizawati, 2016). Beberapa penelitian telah dilakukan dalam pengaplikasian suhu basal tubuh untuk mendeteksi masa subur pada wanita diantaranya sebagai berikut. Pada penelitian (Nurimalita et al, 2017) membangun sistem deteksi masa ovulasi pada wanita. Namun, sistem yang dibangun pada penelitian tersebut hanya memantau secara real time dan berkala. Penelitian lain melakukan interpretasi siklus menstruasi berbasis suhu basal tubuh menggunakan metode fuzzy (Ariff et al, 2017)

Pada penelitian Yazed et al, memiliki kelebihan dibanding yaitu merancang sistem yang memprediksi masa subur wanita dengan menggunakan metode fuzzy berbasis suhu basal tubuh (Yazed et al, 2017). Pada penelitian ini didapatkan hasil akurasi prediksi masa subur yang tinggi akan tetapi pada penelitian ini monitoring dan charting tidak terintegrasi oleh device apapun sehingga tidak dapat dilihat secara otomatis. Pada penelitian perkiraan menstruasi dengan menggunakan metode state-space modeling berbasis seri waktu pada pengukuran suhu basal tubuh (Fukaya, 2017). Di penelitian ini, menjelaskan hari fluktasi, memprediksi panjang satu siklus menstruasi serta membandingkan akurasi prediksi dari metode-metode yang sudah ada sebelumnya. Hasil pada penelitian menunjukkan hasil akurasi yang lebih baik dari metode-metode yang sudah ada sebelumnya. Oleh karena itu pada penelitian ini diharapkan nantinya dapat membantu wanita dalam memprediksi kesuburan mereka secara akurat, efektif, dan efisien.

\section{Pembahasan}

Teknik prediksi dalam pemodelan state-space yaitu dengan menggunakan teknik filter kalman. Filter kalman merupakan suatu pendekatan untuk memprediksi sesuatu dari state vector. Filter kalman pertama kali diperkenalkan oleh Rudolf E. Kalman (1960). Filter kalman adalah bagian dari model state-space yang dapat diterapkan kedalam model prediksi. Tahapan prediksi terdiri dari pembentukan dugaan awal dari state kemudian memperbaharui dengan menambahkan koreksi pada dugaan awal. Baiknya observasi awal menentukan besarnya koreksi. 


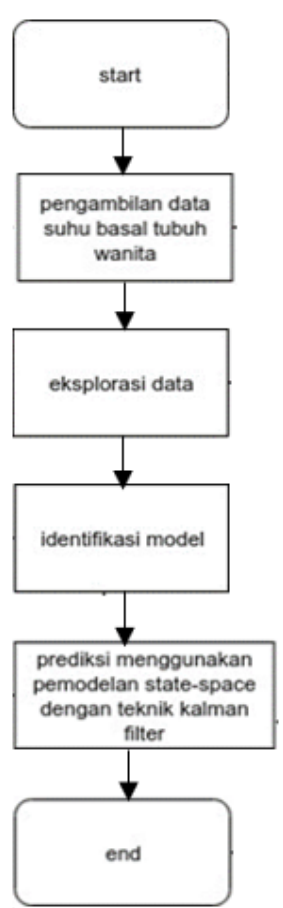

Gambar 1. Tahapan Prediksi Pemodelan State Space

Gambar 1 merupakan tahapan prediksi dari pemodelan state-space. Langkah awal yang dilakukan yaitu dengan melakukan pengumpulan data suhu basal tubuh wanita. Data yang digunakan dalam penelitian ini adalah data suhu basal tubuh menggunakan pengukuran terhadap 2 wanita dengan usia 20 sampai 45 tahun di lingkup Universitas Muhammadiyah Malang. Pengukuran suhu tidak dipengaruhi oleh cuaca atau iklim sekitar. Pengukuran tidak dipengaruhi oleh hormon wanita yang tidak stabil sehingga tidak menimbulkan siklus menstruasi yang kacau. Data diambil dalam jangka waktu 3 bulan dimana setiap harinya diambil masing-masing 1 kali suhu tubuh. Pengambilan data menggunakan alat pengukur suhu yaitu termometer digital dan pengukuran dilakukan dengan cara menempelkan termometer pada ketiak. Setelah data didapatkan data dibagi menjadi 2, Pembagian data akan dilakukan seperti tabel 1.

Tabel 1. Pembagian Data

\begin{tabular}{|l|l|l|}
\hline No & Data Training & Data Testing \\
\hline 1 & 1 siklus & 1 siklus \\
\hline 2 & 2 siklus & 1 siklus \\
\hline
\end{tabular}

Pada penelitian ini analisis dan hasil prediksi diimiplementasikan dengan bahasa pemrograman $\mathrm{R}$ dan perangkat lunak yang digunakan yakni $\mathrm{R}$ Studio. Eksplorasi data bertujuan untuk melihat secara detail informasi tentang data yang diujikan. Mulai dari deskriptif data, plotting data serta langkah-langkah yang akan dijadikan acuan sebelum proses prediksi. Pada tabel 2 di bawah merupakan hasil pengukuran suhu basal tubuh responden 1 (32 tahun). Pengukuran dilakukan dari bulan februari sampai bulan april untuk mendapatkan 2 siklus masa subur. Dengan panjang tiap siklusnya adalah 29 hari. Pada gambar 2 dan 3 merupakan plot deret waktu siklus ke-1 dan ke-2 responden 1. Dapat dilihat pada gambar 4.6 diperkirakan masa subur responden 1 di siklus ke-1 terjadi pada hari ke-13.

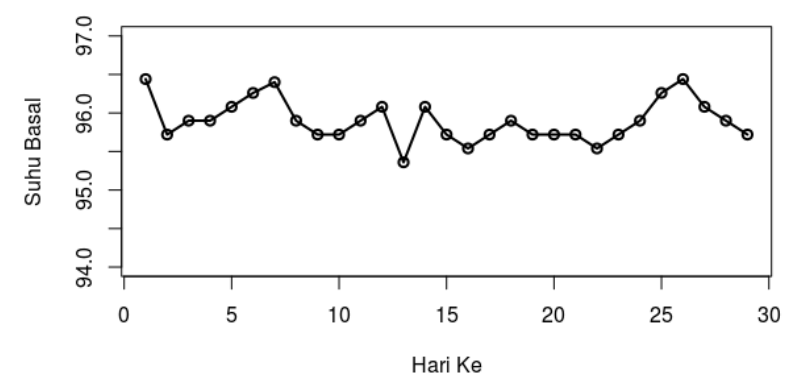

Gambar 2. Plot Data Deret Waktu Hasil Pengukuran Suhu Basal Tubuh Responden 1 Siklus ke-1

Sedangkan pada siklus ke-2 masa subur diperkirakan terjadi pada hari ke-12, meski terjadi penurunan juga di hari ke-15 dan 19 akan tetapi kenaikan suhu setelah harihari tersebut tidak signifikan.

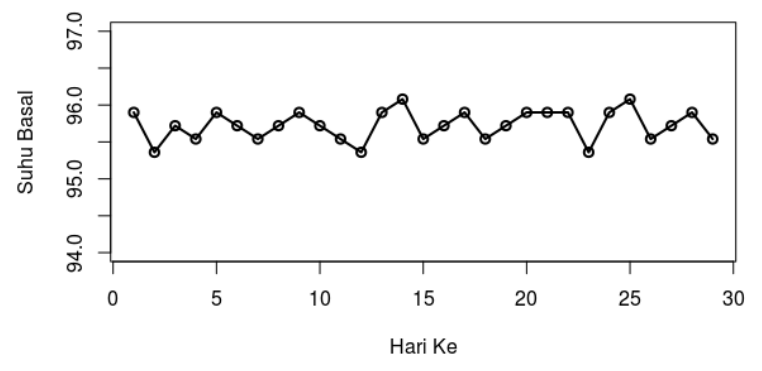

Gambar 3. Plot Data Deret Waktu Hasil Pengukuran Suhu Basal Tubuh Responden 2 Siklus ke-2

Pada tabel 3 di bawah merupakan hasil pengukuran suhu basal tubuh responden 2 (28 tahun). Pengukuran dilakukan dari bulan februari sampai bulan mei untuk mendapatkan 3 siklus masa subur. Dengan panjang tiap siklusnya adalah 31 hari. Pada gambar 4, 5, dan 6 merupakan plot deret waktu siklus ke-1, ke-2, dan ke-3 responden 1. Pada siklus ke-1 masa subur responden 2 kemungkinan terjadi antara hari ke-12 dan 14. Sedangkan pada siklus ke-2 sulit untuk diperkirakan kapan terjadinya masa subur dikarenakan terjadi penurunan yang stabil setelah hari ke-10. Kemungkinan masa subur terjadi lebih dari satu hari[2].

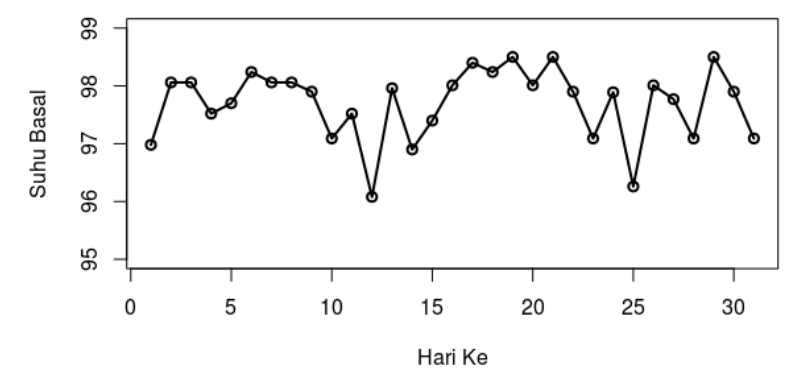

Gambar 4. Plot Data Deret Waktu Hasil Pengukuran Suhu Basal Tubuh Responden 2 Siklus ke-1

Sedangkan pada siklus ke-3 kemungkinan masa subur terjadi pada hari ke-14. 


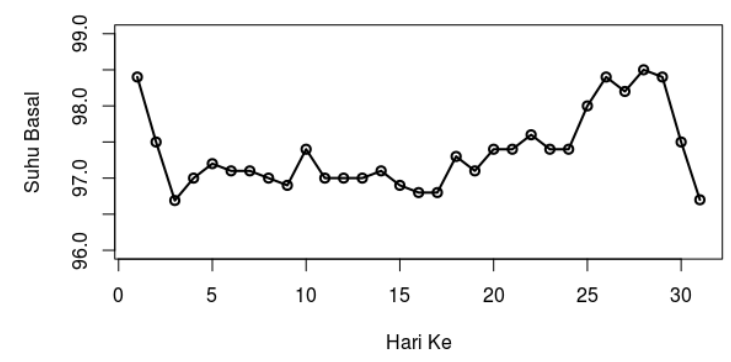

Gambar 5. Plot Data Deret Waktu Hasil Pengukuran Suhu Basal Tubuh Responden 2 Siklus ke-2

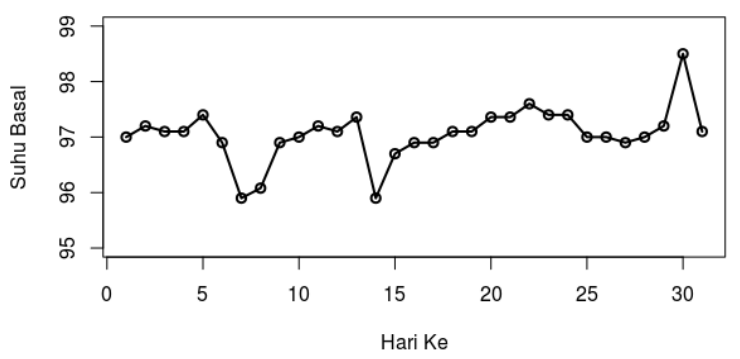

Gambar 6. Plot Data Deret Waktu Hasil Pengukuran Suhu Basal Tubuh Responden 2 Siklus ke-3

Tahap Kestasioneran Data dan Identifikasi Model diidentifikasi dengan uji autokorelasi (ACF) dan parsial autokorelasi (PACF)[9].
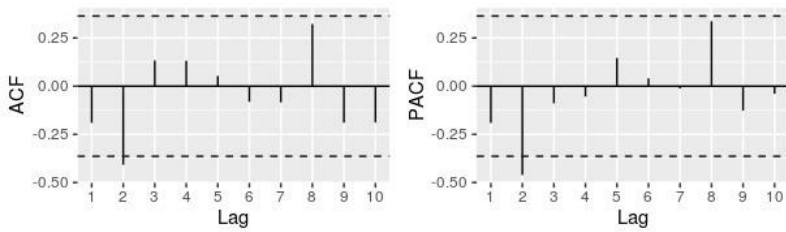

Gambar 7. Plot ACF dan PACF Responden 1

Pada gambar 7 dapat dilihat bahwa pada lag kedua nilainya melewati batas bawah, akan tetapi data telah stasioner karena pada lag ketiga dan seterusnya tidak melewati batas atas dan bawah (stasioner dalam rataan)[9]. Hal yang sama juga dapat dilihat dari plot ACF dan PAFC responden 2 (gambar 8) hanya pada lag pertama yang melewati batas.
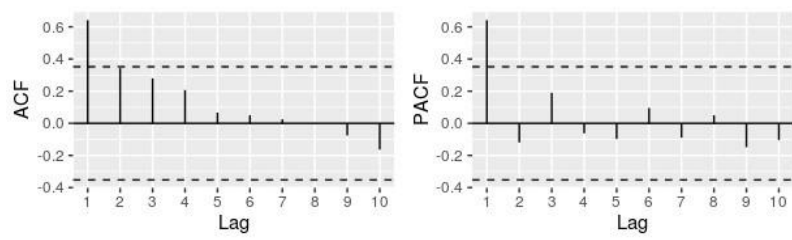

Gambar 8. Plot ACF dan PACF Responden 2

Pada tahap selanjutnya setelah data stasioner dilakukan pencarian model tebaik. Penentuan model dilihat dari hasil ACF dan PACF diatas, maka didapatkan pemodelan ARIMA dengan yang ditunjukkan pada Tabel 2.
Tabel 2. Model ARIMA

\begin{tabular}{|l|l|l|l|}
\hline Responden & Model & Parameter & Koefisien \\
\hline 1 & $(0,0,2)$ & MA(1) & -0.1361 \\
& & MA(2) & -0.4136 \\
\hline 2 & $(1,0,0)$ & AR(1) & 0.3363 \\
\hline
\end{tabular}

Tahap pengujian dilakukan dengan melakukan penentuan orde optimal pada tiap model. Prediksi menggunakan teknik kalman filter dilakukan dengan cara memisah data, yaitu data siklus pertama $\left(\mathrm{Z}_{\mathrm{t}-1}\right)$ dan data periode siklus kedua $\mathrm{Zt}$, jika diimplementasikan pada model state-space menjadi persamaan (1).

Persaman (1) menunjukkan pemodelan state-space untuk memprediksi siklus masa subur pada periode selanjutnya. Panjang siklus masa subur untuk data prediksi diasumsikan sama dengan panjang siklus masa subur pada periode sebelumnya. Hasil prediksi pada responden 1 ditunjukkan pada Gambar 9.

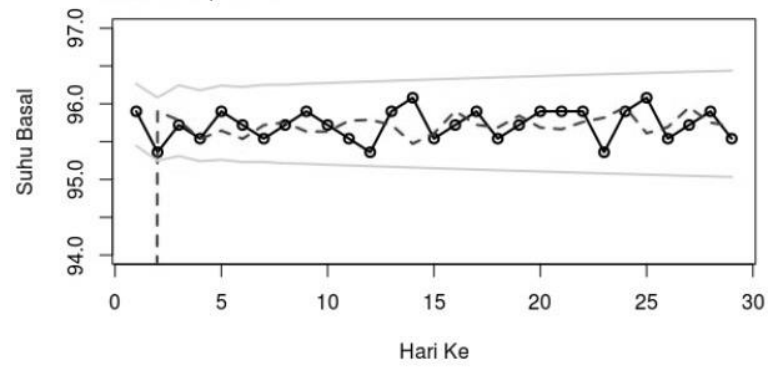

Gambar 9. Plot Data Aktual dengan Data Prediksi Responden 1

Pada gambar 9 hasil prediksi dapat terlihat lebih jelas, kemungkinan masa subur pada periode berikutnya terjadi antara hari ke-13 dan 14. Dikarenakan pada gambar 8 terlihat garis merah (hasil data prediksi) turun secara signifikan dan hari setelahnya terjadi kenaikan. Hasil prediksi dan data aktual untuk responden 2 ditunjukkan pada Gambar 10.

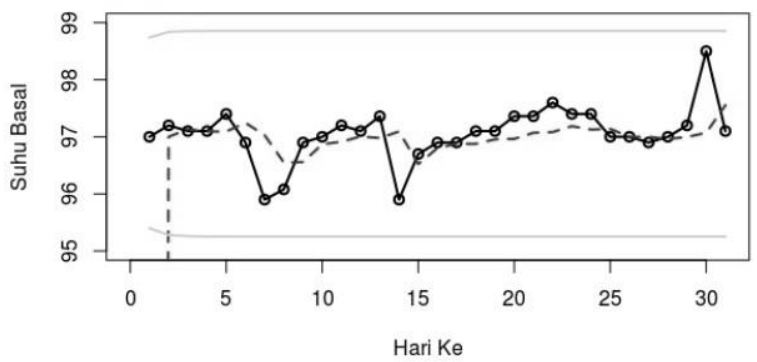

Gambar 10. Plot Data Aktual dengan Data Prediksi Responden 2

Pada gambar 10 terlihat bahwa kemungkinan masa subur pada periode berikutnya terjadi antara hari ke-13 dan 14 . Dari gambar 9 hasil prediksi juga mendekati data aktual, dapat ditarikan kesimpulan grafik dari keselurahan data yang diuji hampir serupa dengan data aktual. Hal ini menjadi indikasi filter kalman memiliki akurasi prediksi 
yang baik untuk memprediksi periode siklus berikutnya dalam siklus masa subur wanita. Selanjutnya setelah melihat hasil secara visualisasi dilihat juga analisis ketepatan prediksi secara matematis. Metode yang dijadikan pengukuran hasil prediksi yaitu dengan menggunakan Mean Absolute Percent Error (MAPE). Dimana hasil yang semakin kecil akan menunjukan hasil prediksi yang semakin baik[7]. Hasil evalusi ditunjukkan pada Tabel 3.

Tabel 3. Hasil MAPE

\begin{tabular}{|l|l|}
\hline Responden & MAPE \\
\hline 1 & 3.665515 \\
\hline 2 & 3.546158 \\
\hline
\end{tabular}

Tabel 3 menunjukkan bahwa persentase kesalahan prediksi masa subur wanita menggunakan pemodelan state space berbasis suhu basal tubuh sudah cukup baik.

\section{Kesimpulan}

Prediksi masa subur wanita dengan pemodelan statespace berbasis suhu basal tubuh memiliki hasil presentase yang sangat baik dikarenakan semua hasil prediksi dengan MAPE dibawah 5\% selain itu dapat dilihat juga dengan hasil visualisasi data, perbandingan antara aktual dan prediksi tidak jauh berbeda. Penelitian ini menunjukkan bahwa pemodelan state-space tepat digunakan untuk memprediksi masa subur pada wanita berbasis suhu bsal tubuh. Dari hasil perhitungan yang mengukur ketepatan prediksi, hasil paling baik dari metode presentase rata-rata kesalahan adalah responden 1 dengan presentase sebesar $3,5 \%$.

Penelitian ini hanya menjadi awal agar dapat dikembangkan lagi dengan penambahan indikasi pembentukan model prediksi ARIMA agar representasi pemodelan state-space jadi lebih baik. Serta penambahan variabel dan banyaknya data siklus masa subur pada wanita agar prediksi periode masa subur bisa lebih banyak dan meminimalisir kesalahan ketepatan prediksi.

Diharapkan diadakan penelitian kembali untuk pembuatan gabungan antara aplikasi dan piranti cerdas yang dapat mengukur suhu basal tubuh secara otomatis kemudian juga dapat secara langsung memprediksi periode berikutnya secara real time. Sistem nantinya juga akan membantu memudahkan wanita untuk melihat hasil masa subur pada periode siklus sekarang dan kedepannya.

\section{Daftar Pustaka}

AMINNUDIN YF, APRILIANI E, WAHYUNINGSIH N. Penerapan Filter Kalman dalam Perbaikan Hasil Prediksi Return Harga Minyak Mentah Dunia dengan Model Arima. J Sains dan Seni ITS. 2018;

FUKAYA K, KAWAMORI A, OSADA Y, KITAZAWA $\mathrm{M}$, ISHIGURO $\mathrm{M}$. The forecasting of menstruation based on a state-space modeling of basal body temperature time series. Stat Med. 2017;

IKA P. Merencanakan atau Mencegah Kehamilan secara Efektif dan Efisien dengan Monitor Ovulasi.
Seminar Nasional Fakultas Ilmu Kesehatan. 3741;2018.

MUHAMMAD SYUKRI MODH YAZED, FARHANAHANI MAHMUD, MARLIA MORSIN. Fuzzy logic system for BBT based fertility prediction. J Fundam Appl Sci. 2017;

NASON GP. Stationary and non-stationary time series. In Mader H, Coles SC, editors, Statistics in Volcanology. The Geological Society. 129 $142 ; 2006$

NURIMALITA, RISQIWATI . Deteksi Siklus Ovulasi Wanita dengan Monitoring Suhu. Seminar Nasional Teknologi dan Rekayasa (SENTRA). 2017;

OWENS DH. State space models. In: Advances in Industrial Control. 2017

YAZED MSM, ZAINODIN AF, MAHMUD F. Fuzzy logic system for menstrual cycle interpretation based on BBT data. Int J Integr Eng. 2017

YULIZAWATI, AYU N, BUSTAMI LE, DETTY I, ALDINA AI. Implementasi Konsep Siklus Menstruasi Pada Konseling Skrening Premarital. Journal of Midwifery: Reasearch and Practice. Vol. 1;No. 1;1-11;2016 